\title{
The Effect of $\gamma$-Cyclodextrin Addition in the Self-Assembly Behavior of Pyrene Labeled Poly(acrylic) Acid with Different Chain Sizes
}

\author{
TELMA COSTA, J. S. SEIXAS DE MELO \\ Department of Chemistry, University of Coimbra, 3004-535 Coimbra, Portugal
}

Received 4 April 2007; accepted 8 October 2007

DOI: 10.1002 / pola.22480

Published online in Wiley InterScience (www.interscience.wiley.com).

\begin{abstract}
The interaction between poly(acrylic acid) polymers (PAA) of low- (2000 g/ $\mathrm{mol})$ and high- $(450,000 \mathrm{~g} / \mathrm{mol})$ molecular weight $\left(M_{\mathrm{w}}\right)$ hydrophobically modified with pyrene (PAAMePy) and $\beta$ - and $\gamma$-cyclodextrins ( $\beta$-CD, $\gamma$-CD) was investigated with fluorescent techniques. The interaction with $\beta$-CD promotes little variation in the spectral and photophysical behavior of the polymer, whereas significant changes are observed upon addition of $\gamma$-CD. The degree of inclusion (between the pyrene groups of the polymer and the cyclodextrins) is followed through the observation of the changes in the absorption, excitation (collected in the monomer and excimer emission regions) and emission $\left(I_{\mathrm{E}} / I_{\mathrm{M}}\right.$ ratio) spectra and from time-resolved data. Within the studied range of $\gamma$-CD concentration, the fluorescence decays of the long chain (high $M_{\mathrm{w}}$ ) PAAMePy polymers were found tri-exponential in the monomer and excimer emission regions in agreement with previous studies. In the case of the low $M_{\mathrm{w}} \mathrm{PAA}-$ MePy polymers, tri-exponential decays were observed at the monomer and excimer emission wavelengths. However, when a $\gamma$-CD concentration of 0.01 and $0.03 \mathrm{M}$ is reached for, respectively, the low- and high-labeled pyrene short chain (low $M_{\mathrm{w}}$ ) polymers, the fluorescence decays in the excimer region become biexponential (two excimers) with no rising component, thus showing that all pyrene groups are encapsulated (and preassociated) into the $\gamma$-CD cavity. In the case of the high $M_{\mathrm{w}}$ polymers, the addition of $\gamma$-CD has been found to change the level of polymer interaction from pure intramolecular (water in the absence of cyclodextrin) to a coexistence of intrawith intermolecular interactions. () 2008 Wiley Periodicals, Inc. J Polym Sci Part A: Polym Chem 46: 1402-1415, 2008
\end{abstract}

Keywords: cyclodextrins; excimer; fluorescence; kinetics (polym.); photophysics; poly(acrylic acid); polymer photophysics; pyrene

\section{INTRODUCTION}

Hydrophobically modified polymers (HMP) are water-soluble polymers modified with hydrophobic moieties, which can be randomly distributed

Correspondence to: J. S. Seixas de Melo (E-mail: sseixas@ ci.uc.pt)

Journal of Polymer Science: Part A: Polymer Chemistry, Vol. 46, 1402-1415 (2008) ๑) 2008 Wiley Periodicals, Inc. or located in precise locations (usually in the terminal positions) of the polymer chain. Because of their capacity to form hydrophobic microdomains by inter- and intramolecular interaction, HMP are very important in several industrial applications, for example, surface modification, rheology control, and dispersion stabilization. ${ }^{1,2}$ Because of its unique characteristics, long singlet lifetimes, excimer formation, vibronic structure dependence with polarity, ${ }^{2-4}$ 


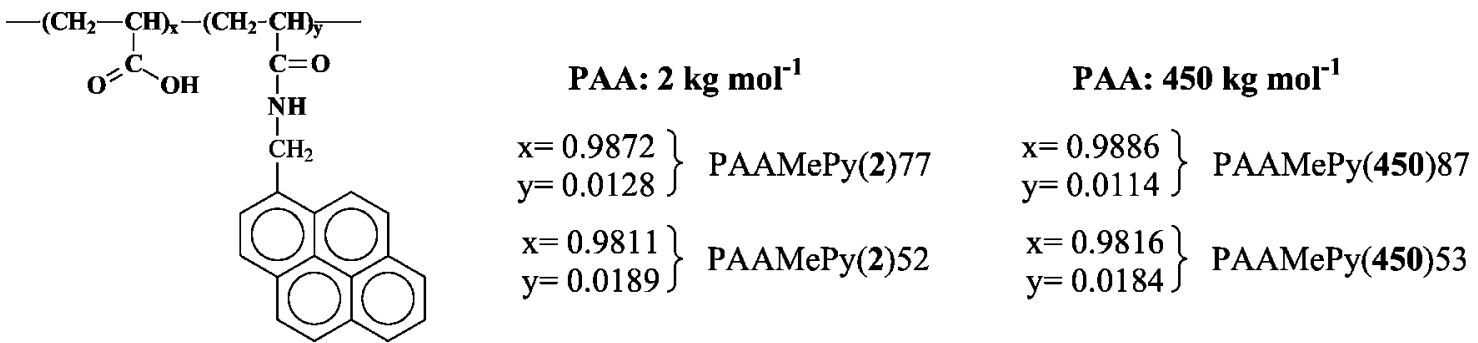

Scheme 1. Relative compositions (PAA versus pyrene unimer units) of polymers used and their corresponding acronyms.

pyrene has a widespread use as hydrophobic moieties in the colloidal domain. One of the most useful relations is the excimer-to-monomer ratio $\left(I_{\mathrm{E}} / I_{\mathrm{M}}\right)$, which can be directly related with movements of the polymer where the probe is found tagged to, and can be directly related with the conformation of the polymer chain in solution. Additionally, the vibronically resolved structure of the monomer emission (i.e., the ratio between the first and third vibronic band of monomer emission, $I_{1} / I_{3}$ ratio) exhibits high sensitivity to changes in the polarity of the local environment felt by the chromophore and has been extensively used as a polarity scale..$^{5-13}$

Previous works showed that the intra- ${ }^{7,14-16}$ and intermolecular ${ }^{17-22}$ interactions induced by the hydrophobes attached to the polymer chain are very dependent on the $\mathrm{pH}$, solvent, temperature, and presence of amphiphilic molecules, ${ }^{23-}$ ${ }^{25}$ such as surfactants, block copolymers ${ }^{26}$ and cyclodextrins (CDs). ${ }^{22}$ Addition of CDs to hydrophobically modified polymers solutions have also shown to dramatically change the intramolecular association behavior of the polymers. ${ }^{27}$

CDs have been widely used in pharmaceutical science, catalyses, pesticides, foods, cosmetics, and other areas. ${ }^{27-32}$ They are macrocyclic oligomers of $\alpha$-D-glucose and shaped like truncated cones with the primary hydroxyl rim of the cavity opening having somewhat reduced diameter when compared with the hydroxy rim. The exterior of the CD is fairly polar and its interior non polar. ${ }^{31,33,34}$ This characteristic makes them of particular interest because of their ability to form host:guest complexes with different guest species. ${ }^{35,36}$ The driving forces involved in the inclusion complexation of CD should include electrostatic, van der Waals, and hydrophobic interactions, together with hydrogen bonding and charge-transfer interactions. ${ }^{34}$ The three most common CDs are: $\alpha$-CD (6 glucose units, $4.5 \AA$ ), $\beta$-CD (7 glucose units, 7.8 $\AA$ ), and $\gamma$-CD (8 glucose units, $9.5 \AA$ ). ${ }^{27,31,34}$
In aqueous solution, it is known that CDs form inclusion complexes with hydrophobic molecules, such as pyrene and naphthalene, and amphiphilic molecules, such as surfactants ${ }^{37}$ and hydrophobically modified polymers. ${ }^{22,38,39}$ Inclusion guest:CD complexes of 1:1, 1:2, 2:1, and 2:2 have been reported. Several studies were performed involving pyrene and $\gamma$-CD. Two pyrene units are able to go inside the $\mathrm{CD}$ cavity forming a 2:1 (Py: $\gamma-\mathrm{CD})$ inclusion complex with the appearance of the structureless long-wavelength excimer emission band. ${ }^{27,28,35,40,41}$

\section{EXPERIMENTAL}

\section{Synthesis and Materials}

The synthesis procedure of hydrophobic modification of the four poly(acrylic acid) polymers with 1-pyrenylmethylaminehydrochloride is described in ref. 42. The poly(acrylic acid) polymers (PAA) with nominal weight $M_{\mathrm{n}}=2000$ and $450,000 \mathrm{~g} / \mathrm{mol}$ (Aldrich), 1-pyrenylmethylamine hydrochloride (Aldrich), and all reagents and solvents used were obtained from commercial sources and used as received. The pyrene $(\mathrm{Py})$ labeling content was determined by UV spectroscopy by comparison with the parent compound 1-pyrenylmethylamine $\left(\varepsilon=37,070 \mathrm{M}^{-1}\right.$ $\mathrm{cm}^{-1}$ in methanol). The nomination of the polymers was based on the molecular weight of the PAA polymer and on the Py content of the polymers. The polymers investigated here are denoted as PAAMePy(2)52, PAAMePy(450)53, PAA$\operatorname{MePy}(2) 77$, and PAAMePy(450)87, where 52, 53, 77 , or 87 corresponds to number of PAA monomer units per Py chromophore, respectively, and 2 and 450 stands for the 2000 and $450,000 \mathrm{~g} / \mathrm{mol}$ polymers, respectively (Scheme 1).

Beta (Fluka) and gamma cyclodextrins (Aldrich) were used as received. 
Water used for the polymer solutions was twice distilled and passed through a Millipore apparatus. The measured $\mathrm{pH}$ values were obtained with a Crison micropH 2000 and adjustments of the hydrogen ion concentration of the solutions were made with dilute $\mathrm{HCl}$ solutions. The chromophore concentration of the aqueous PAAMePy solutions ranged from $10^{-5}$ to $10^{-6} \mathrm{M}$, which is well below the critical value for coil overlap, $c^{*}$. ${ }^{43}$

\section{Absorption and Fluorescence Measurements}

Absorption and fluorescence spectra were recorded on Shimadzu UV-2100 and Jobin-Yvon SPEX Fluorog 3-22 spectrometers, respectively. All the fluorescence spectra were corrected for the wavelength response of the system. Fluorescence decays were measured using a home-built TCSPC apparatus as described elsewhere, ${ }^{44}$ except that as excitation source, a Horiba-JI-IBH NanoLED, $\lambda_{\text {exc }}=339 \mathrm{~nm}$, was used. The fluorescence decays were analysed using the modulating functions method of Striker. ${ }^{45}$ Temperature control was achieved using a home-built system based on cooled nitrogen and electric heating.

\section{RESULTS}

\section{PAAMePy(2) and PAAMePy(450) Polymers in Aqueous Solution}

Previous studies on the PAAMePy(2) and PAA$\mathrm{MePy}(450)$ polymers in aqueous solution showed that their behavior is dependent on the $\mathrm{pH}$, solvent, degree of labeling and size of the PAA chain. ${ }^{18,21,42,46}$ The absorption and fluorescence spectra (excitation and emission) displays the characteristic pyrene bands, found to be $\mathrm{pH}$ dependent. ${ }^{42}$ In the case of the fluorescence spectra, in addition to the vibronically resolved monomer (with maxima $\approx 374 \mathrm{~nm}$ ) band, the structureless excimer band (with maxima centered at $\approx 480 \mathrm{~nm}$ ) is also visible.

With the long chain polymers [PAAMePy (450)], the excimer-to-monomer $\left(I_{\mathrm{E}} / I_{\mathrm{M}}\right)$ ratio decreases in the alkaline region, which was shown to be a consequence of the progressive ionization of the carboxylic $(\mathrm{COOH})$ groups in these, and related, PAA polymers labeled with fluorescent probes. ${ }^{17,21,24,25,42,43,47}$ This happens because the electrostatic repulsion between the carboxylate $\left(\mathrm{COO}^{-}\right)$groups expands the polymer chain, affecting the distance between adjacent pyrene groups with less excimer (dynamic and static) being formed at higher $\mathrm{pH}$ values. In the case of the short chain PAAMePy polymers an opposite trend in the variation of the $I_{\mathrm{E}} / I_{\mathrm{M}}$ with $\mathrm{pH}$ was observed ${ }^{42,48}$ and explained on the basis of the adoption of a "micelle-like" conformation by the PAAMePy(2) polymers creating an "hydrophobic" core where the pyrene groups could be located. ${ }^{42}$ Similar formation of coreshell micelles was also observed with ionic polyurethanes labeled with pyrene. ${ }^{49}$

\section{Addition of $\gamma$-Cyclodextrin to Aqueous Solutions of PAAMePy(2) and PAAMePy(450)}

\section{Absorption Spectra}

Figure 1(A) shows the variation of the absorption spectra for PAAMePy(2)77 and PAA$\mathrm{MePy}(450) 87$ polymers (top and bottom panels, respectively) with $\gamma$-cyclodextrin (concentration of $\gamma$-CD ranging from $\approx 0.005$ to $\approx 0.08 \mathrm{M}$ ), at $\mathrm{pH}=3.5$. From the observation of Figure 1(A), where the PAA polymer concentration is constant, it can be seen that the gradual addition of $\gamma$-CD leads to significant changes in the absorption bands. For the four studied polymers, the $P_{A}$ parameter (defined as the peak-to-valley ratio) ${ }^{17}$ decreases with the addition of $\gamma$-CD [see insets in Fig. 1(B)]. The differences observed in the $\mathrm{S}_{0} \rightarrow \mathrm{S}_{2}$ transition indicate contributions from the absorption of ground-state dimers (GSD; a band that is buried underneath the more intense pyrene monomer band). ${ }^{17}$ In addition to the changes in the relative optical density values, the long chain PAAMePy(450) polymers also display a blue shift from 345.6 to $344.2 \mathrm{~nm}$ on going from low to high $\gamma$-CD concentrations. However, in the case of the short chain polymers this shift is not as pronounced as with the long chain polymers.

\section{Fluorescence (Excitation and Emission) Spectra}

Additional information concerning the level of GSD comes by comparison between the excitation fluorescence spectra collected at the monomer and excimer emission wavelengths. ${ }^{2,17}$ The differences consist of a more or less pronounced displacement of the wavelength maximum of the two spectra $\left(\Delta \lambda_{2}\right)$; differences in the peak-to-valley ratio relative to the $(0,1)$ transition observed in the monomer $\left(P_{\mathrm{M}}\right)$ and excimer $\left(P_{\mathrm{E}}\right)$ excitation spectra, respectively; and also from a significant broadening of the $\mathrm{S}_{0} \rightarrow \mathrm{S}_{1}$ absorption band, leading to a more pronounced absorption in the red part of the spectra. ${ }^{2,17,18,50,51}$ When 

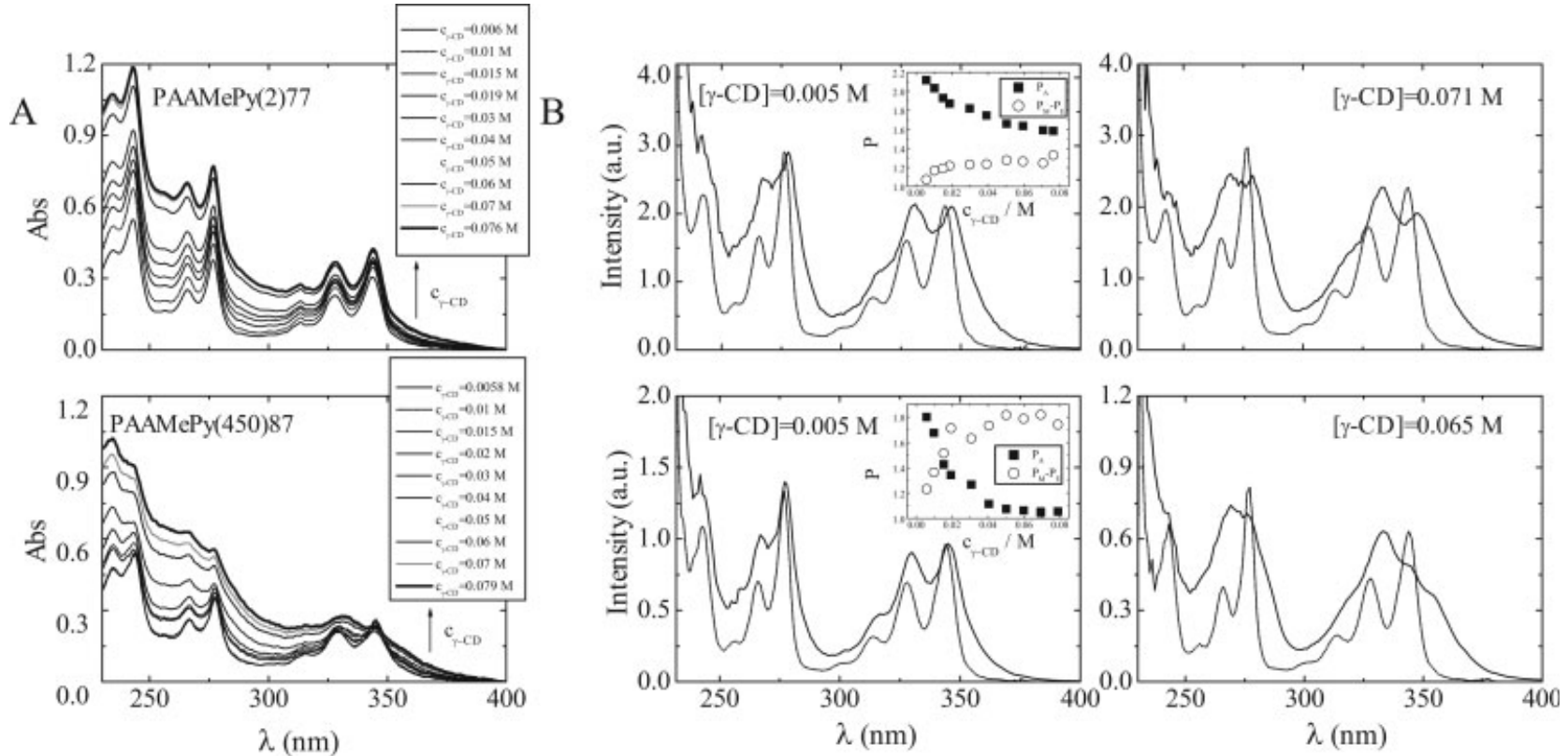

Figure 1. Absorption (A) and fluorescence excitation (B) spectra for PAAMePy(2)77 (top panels) and PAAMePy(450)87 (bottom panels) obtained at two different emission wavelengths, $374 \mathrm{~nm}$ (dashed line) and $520 \mathrm{~nm}$ (full line) for different concentrations of $\gamma$-cyclodextrin at $\mathrm{pH}=3.5$ and $T=293 \mathrm{~K}$. The insets in $\mathrm{B}$ correspond to the dependence of the $P_{A}$ and $P_{\mathrm{M}}-P_{\mathrm{E}}$ parameters on the $\gamma$-cyclodextrin concentration.

GSDs are absent, i.e., when the diffusive encounter between two pyrene molecules (one in the ground-state with one in the excited state) is the only viable route for excimer formation (a purely dynamic process) then the two excitation spectra must superimpose. ${ }^{2,17,42}$ However, as can be seen from Figure 1(B) (for low and high $\gamma$-CD concentration), this is not what happens with the excitation spectra of the PAAMePy polymers. Moreover the differences between the spectra collected at $\lambda_{\mathrm{em}}=375 \mathrm{~nm}$ and $\lambda_{\mathrm{em}}=520$ $\mathrm{nm}$ become clearly more pronounced with the addition of $\gamma-\mathrm{CD}$; these differences are mirrored by the increase in the $P_{\mathrm{M}}-P_{\mathrm{E}}$ values [see insets in Fig. 1(B)].

The addition of $\beta$-CD $(0.0005-0.008 \mathrm{M})$ to the PAAMePy polymers solution promotes no changes on the absorption spectra and $I_{\mathrm{E}} / I_{\mathrm{M}}$ ratio (data not shown). This clearly establishes that in this case, as expected, the $\beta$-CD only allows the inclusion of a single pyrene unit (formation of a 1:1 inclusion complex) inducing minor changes in the photophysical properties of the PAAMePy polymers.

On the other hand, the addition of $\gamma$-CD clearly leads to changes in the emission spectra of the PAAMePy polymers mirrored by the gradual increment of the excimer emission (Fig. 2, left pan- els). The variation of the $I_{\mathrm{E}} / I_{\mathrm{M}}$ ratio with $\gamma$-CD is also presented in Figure 2 (middle hand panels), where it can be observed that this ratio increases with the concentration of $\gamma$-CD. With the PAA$\mathrm{MePy}(2)$ polymers the $I_{\mathrm{E}} / I_{\mathrm{M}}$ ratio is constant up to a certain $\gamma$-CD concentration. However, this behavior is not observed with the long-size chain PAAMePy(450) polymers. Indeed, with the PAA$\mathrm{MePy}(450)$ polymers, the $I_{\mathrm{E}} / I_{\mathrm{M}}$ ratio gradually increases, never reaching a plateau. It is worth noting that the increase in the excimer emission, which occurs with the short and long PAA chain polymers, is also accompanied by $\mathrm{a} \approx 6-7 \mathrm{~nm}$ blue-shift of the emission wavelength maximum. Moreover, from the dependence of the $I_{\mathrm{E}} / I_{\mathrm{M}}$ ratio with the excitation wavelength $\left(\lambda_{\text {exc }}\right)$, qualitative information on the presence (and level) of GSD can also be obtained. In fact, from Figure 2 (middle hand panels) it can be seen that the $I_{\mathrm{E}} / I_{\mathrm{M}}$ ratio increases both with the $\gamma-\mathrm{CD}$ concentration and with the $\lambda_{\text {exc }}$, showing an increment of ground-state association.

Inter- and intrapolymeric interactions are a priori possible to occur with the PAA polymers investigated. However, in water at the low concentrations used, $<0.05 \mathrm{~g} \mathrm{~L}$, interpolymeric interactions are not present since the concentration is well below the limit where it is likely 
A

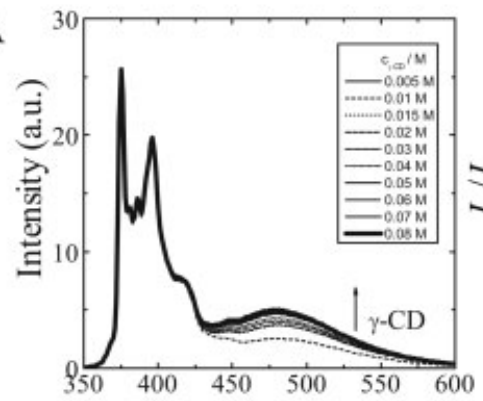

$\lambda(\mathrm{nm})$

B

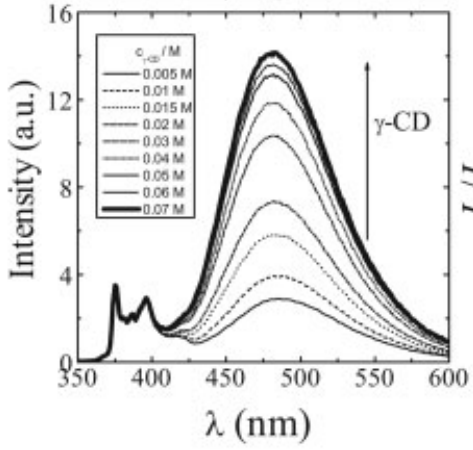

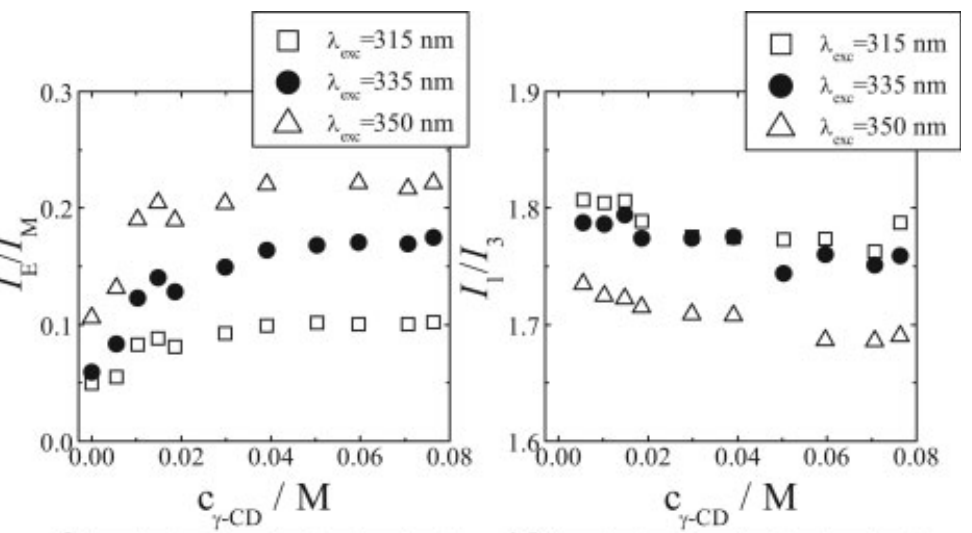
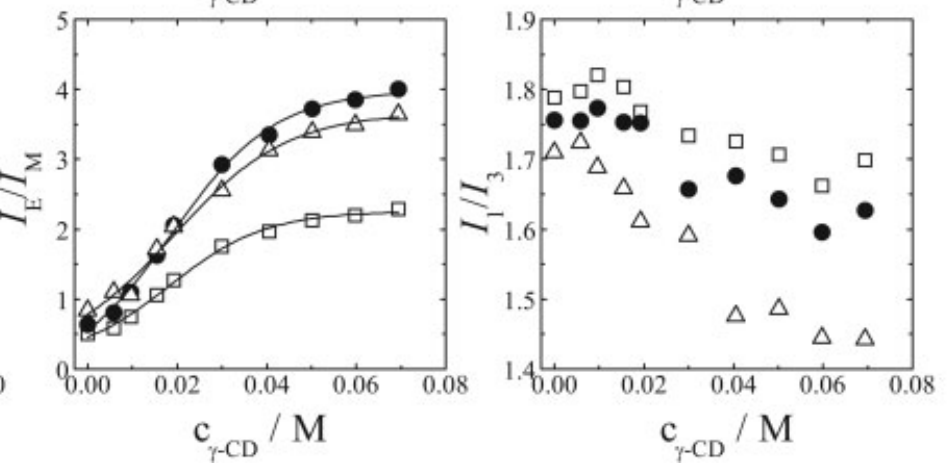

Figure 2. Normalized emission fluorescence spectra $\left(\lambda_{\mathrm{exc}}=335 \mathrm{~nm}\right)$ of the (A) PAA$\mathrm{MePy}(2) 77$ and (B) PAAMePy (450)87 polymers with different concentrations of $\gamma$ $\mathrm{CD}$, at $\mathrm{pH}=3.5$ (left panels). Variation of the $I_{\mathrm{E}} / I_{\mathrm{M}}$ (middle panels) and $I_{1} / I_{3}$ (right panels) ratios, obtained with three different excitation wavelengths as a function of $\gamma$-cyclodextrin concentration at $\mathrm{pH}=3.5$.

that these began to play a determinant role (10 $\mathrm{g} / \mathrm{L}) .{ }^{24}$ Nonetheless, the absence of intermolecular interactions was verified for these polymers in water. ${ }^{42}$ With the addition of $\gamma$-CD new interactions could now be present, including polymer-polymer intermolecular interactions. To check this hypothesis, a study on the dependence of the $I_{\mathrm{E}} / I_{\mathrm{M}}$ ratio with the polymer concentration, at fixed $\gamma$-CD concentration, was performed (Fig. 3). In the case of the PAAMePy(2) polymers, to a constant $\gamma$-CD concentration $(0.03$ $\mathrm{M})$, the increase in the polymer concentration leads to nonsignificant changes in the $I_{\mathrm{E}} / I_{\mathrm{M}}$ ratio, a clear indication of the absence of (new) interpolymer interactions. On the other hand, in the case of the PAAMePy(450) polymers, and contrary to the behavior found in water, ${ }^{17,42}$ the increase of polymer concentration leads to an augment of the $I_{\mathrm{E}} / I_{\mathrm{M}}$ ratio. In the case of the more (pyrene) labeled polymer, $\operatorname{PAAMePy}(450)$ 53 , this behavior can be observed for all $\gamma$-CD concentrations (lowest $\gamma$-CD concentration is 0.5 $\mathrm{mM}$ ). The dependence of the $I_{\mathrm{E}} / I_{\mathrm{M}}$ ratio with the polymer concentration gains gradual importance with the incremental addition of $\gamma-\mathrm{CD}$, as can be seen from the inset in Figure 3(B). For the lowlabeled polymer, PAAMePy(450)87, the dependence of the $I_{\mathrm{E}} / I_{\mathrm{M}}$ ratio versus polymer concentration was only detected at $\gamma$-CD concentrations higher than $\sim 2.5 \mathrm{mM}$ of $\gamma$-CD. Interpolymeric interactions promoted by the presence of $\gamma$-CD were also observed with the analogue PAA$\mathrm{MePy}(150) 55$ polymer; a PAA polymer with an intermediate length chain $\left(M_{\mathrm{w}}=150,000 \mathrm{~g} / \mathrm{mol}\right)$ between the two PAA polymers investigated here. ${ }^{22}$ From these results, it seems fair to conclude that the presence of inter- (in addition to the existent intra-) molecular interactions, promoted by the presence of $\gamma-\mathrm{CD}$, depend on the hydrophobicity, that is to say on the molecular weight and degree of labeling, of the polymer.

\section{Time-Resolved Fluorescence}

Figure 4(A) shows the fluorescence decays (fitted with an individual analysis procedure ${ }^{42}$ ), for the short chain PAAMePy $(2) 77$ polymer with $[\gamma-\mathrm{CD}]$ $=0.006 \mathrm{M}$, at $\mathrm{pH}=3.5$. The fluorescence decays 


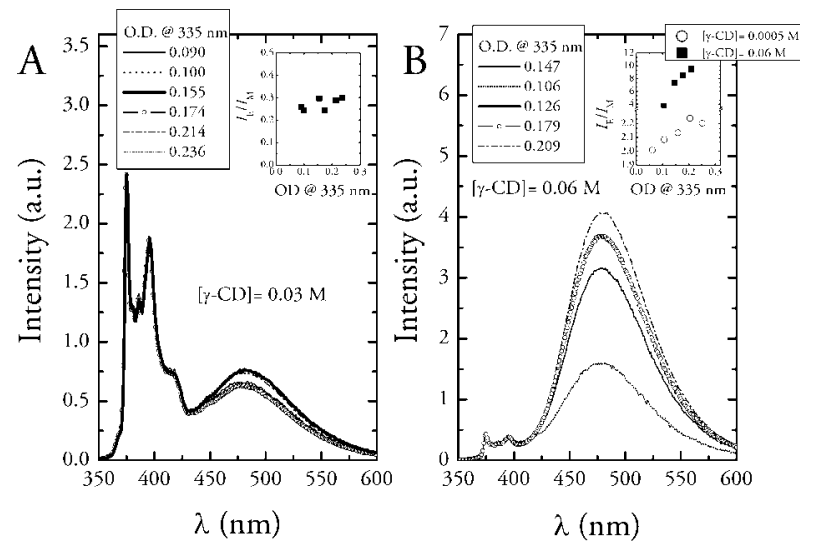

Figure 3. Fluorescence spectra, normalized at the monomer emission maxima, for the (A) PAA$\mathrm{MePy}(2) 52$ and (B) PAAMePy(450)53 polymers at various concentrations, at $\mathrm{pH}=3.5, T=293 \mathrm{~K}$. Shown as insets are the different $I_{\mathrm{E}} / I_{\mathrm{M}}$ ratio values versus the (pyrene) O.D. at $335 \mathrm{~nm}$ in the presence of a constant $\gamma$-CD concentration.

collected at the monomer (375 $\mathrm{nm})$ and excimer $(520 \mathrm{~nm})$ emission wavelengths were fitted with sums of three exponentials although providing four distinct decay times, which were attributed to the emission of free monomers (longest decay time, $\left.\tau_{0}\right)$, monomers that are able to form excimer (shortest decay time, $\tau_{1}$ ), and two conformational different excimers (with the middle decay times, $\tau_{2}$ and $\left.\tau_{3}\right){ }^{22,42}$ As a consequence, the kinetic scheme introduced in refs. 22,42 and briefly presented in the "Discussion" section (see below), for these polymers in aqueous solutions is still valid in the presence of $\gamma$-CD, with the important exception of the short chain polymers at high concentrations of $\gamma$-CD. Indeed, for the PAAMePy(2) polymers, and for $\gamma$-CD values higher than $0.01 \mathrm{M}$ [PAAMePy(2)77] and $0.03 \mathrm{M}$ [PAAMePy $(2) 52]$, the fluorescence decays become monoexponential at the monomer emission wavelength and biexponential at the excimer emission wavelength [see Fig. 4(B)].

\section{DISCUSSION}

\section{Absorption and Steady-State Fluorescence Data}

As it was previously described for the analogous PAAMePy $(150)$ polymers (PAA with $M_{\mathrm{w}}=150$ $\mathrm{kg} \mathrm{mol}{ }^{-1}$ ), the presence of $\gamma$-CD promotes significant changes in the absorption spectra of these polymers, with an inversion of the vibronic modes relative to the $\mathrm{S}_{2} \leftarrow \mathrm{S}_{0}$ transition [Fig. $1(\mathrm{~A})],{ }^{22}$ giving support for the inclusion of two pyrene units in the $\gamma$-CD cavity. ${ }^{27}$ In Figure 1(B) (insets) where the $P_{A}$ parameter is plotted as a function of $\gamma$-CD it can be seen that the $P_{A}$ value for the short chain polymers varies between 2.1 and 1.5, while for the long chain polymers it varies between 1.8 and 1.0. The observed gradual decrease of $P_{A}$ with the addition of $\gamma-\mathrm{CD}$ is indicative of a gradual increment of preassociated pyrene contribution. It is worth noting that $P_{A}$ values close to 3.0 give support for the absence of ground-state association whereas lower values are indicative of preassociated pyrene dimers. ${ }^{2,17}$

The excitation spectra provide additional qualitative information on the presence of GSD. The spectra collected at the monomer and excimer emissions are very different over the whole range of $\gamma$-CD concentrations [see Fig. 1(B)]. In fact, the increase in the difference between the two spectra (increase of $P_{\mathrm{M}}-P_{\mathrm{E}}$ value) agrees well with the results obtained from the absorption spectra $\left(P_{A}\right.$ parameter). This means that at high $\gamma$-CD concentrations the contribution of GSDs increases, which is also mirrored by the increase of the excimer emission band [Fig. 1(B)]. Moreover in Figure 2 (middle hand panels), it is shown that the $I_{\mathrm{E}} / I_{\mathrm{M}}$ ratio increases with the excitation wavelength since GSD predominantly absorb at longer wavelengths. ${ }^{17}$ As mentioned in the "Introduction" section, the $\gamma$ CD cavity can accommodate two pyrene (Py) units in a dimeric form. ${ }^{35}$ The observed increase in the ground-state association is due to their preferred location inside the CD cavity.

With the PAAMePy(2) polymers, the $I_{\mathrm{E}} / I_{\mathrm{M}}$ ratio increases up to $[\gamma-\mathrm{CD}]=0.01$ and $0.03 \mathrm{M}$ for, respectively, the low [Fig. 2(A), middle panels] and high-labeled polymers (data not shown), reaching a plateau thereon; this indicates that all available Py groups are now found inside a $\gamma$-CD cavity forming 1:2 or 1:1 $\gamma$-CD:Py complexes. Consequently, the addition of cyclodextrin clearly favors Py-Py interactions. In contrast, in the case of the long chain PAAMePy(450) polymers this plateau is never reached, and dynamic excimer formation is observed. Since the number of $\gamma$-CD is also higher than the number of pyrene units, the results suggest with the long chain PAAMePy(450) polymers the conformation acquired precludes the complete encapsulation of all pyrene groups. Moreover and since with the PAAMePy(450) polymers intermolecular pyrenepyrene interactions are induced by the presence of $\gamma$-CD it is likely that new conformations 

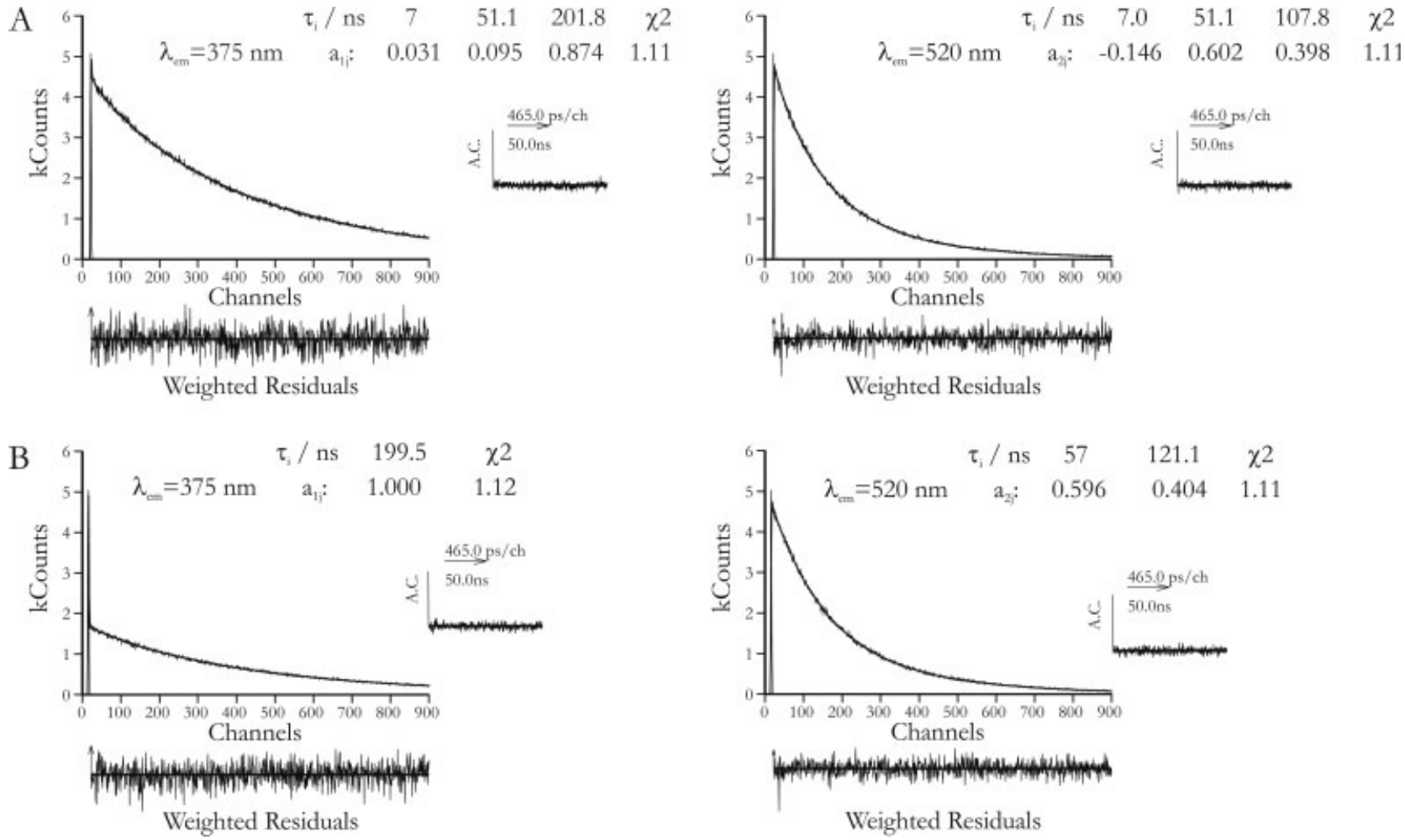

Figure 4. Individual analysis of the fluorescence decays at the monomer ( $\lambda_{\mathrm{em}}$ $=375 \mathrm{~nm})$ and excimer $\left(\lambda_{\mathrm{em}}=520 \mathrm{~nm}\right)$ emission wavelengths, for the PAAMePy $(2) 77$ polymer in the presence of $(\mathrm{A})[\gamma-\mathrm{CD}]=0.006 \mathrm{M}$ and (B) $0.04 \mathrm{M}$ of $\gamma-\mathrm{CD}$, at $\mathrm{pH}=3.5$ and $\lambda_{\text {exc }}=339 \mathrm{~nm}$.

adopted by the polymer will prevent the total encapsulation of all pyrene groups. It is worth noting that other order inclusion complexes, namely $2: 1$ or $2: 2 \gamma$-CD:Py, are not viable since in the case of the PAAMePy polymers one side of the pyrene chromophore is bound to the PAA chain (Scheme 1).

Another important parameter providing relevant information on the system is the $I_{1} / I_{3}$ ratio (ratio of the fluorescence intensity of the first $\left[\mathrm{S}_{0}(v=0) \leftarrow \mathrm{S}_{1}(v=0)\right]$ and the third $\left[\mathrm{S}_{0}(v=1)\right.$ $\left.\leftarrow \mathrm{S}_{1}(v=0)\right]$ vibronic bands) which reflects the polarity of the local medium surrounding pyrene. ${ }^{5,11}$ For the PAAMePy $(2)$ polymers, the $I_{1} / I_{3}$ ratio shows a slight decrease with the $\gamma$-CD concentration, i.e., from 1.78 to 1.76 [Fig. 2(A), left panels] and from 1.82 to 1.77 (data not shown) for the low and highly labeled polymers, respectively, i.e., small variations are observed in the case of the PAAMePy(2) polymers. It is worth remember that in aqueous solution the PAA$\mathrm{MePy}(2)$ polymers adopt a micelle-like conformation, protecting the pyrene groups from the contact with water. ${ }^{42}$ The addition of $\gamma$-CD leads to the encapsulation of the pyrene groups (present both as free monomers or as dimers), leading to a change in this micelle-like structure. ${ }^{42} \mathrm{~A}$ detailed conductivity study of the PAAMePy polymers: $\gamma$-CD interaction, at different $\mathrm{pH}$ values, is currently under investigation and will be the subject of a forthcoming publication. However, preliminary conductivity measurements (data not shown) clearly show a change on the molar conductivity of the $\mathrm{PAAMePy}(2)$ polymers upon addition of $\gamma-\mathrm{CD}$, i.e., the molar conductivity increases with the formation of the Py: $\gamma-C D$ complex. This means that the polyacrylate chain becomes more effective as charge carrier, which constitutes a further evidence of the change in the structure adopted by these polymers in aqueous solution, ${ }^{52}$ in line with the proposed micelle-like structure. ${ }^{42}$

It is noteworthy that the dimensions of the Py groups (10.4 $\AA$ long) relative to the $\gamma$-CD cavity ( $7 \AA$ long) show that the Py group cannot be totally inside the $\gamma$-CD cavity, ${ }^{28,35}$ remaining partially in contact with water; as a consequence, the environment probed by pyrene is rather polar even at high CD concentration. For the long size chain polymers the $I_{1} / I_{3}$ ratio pro- 

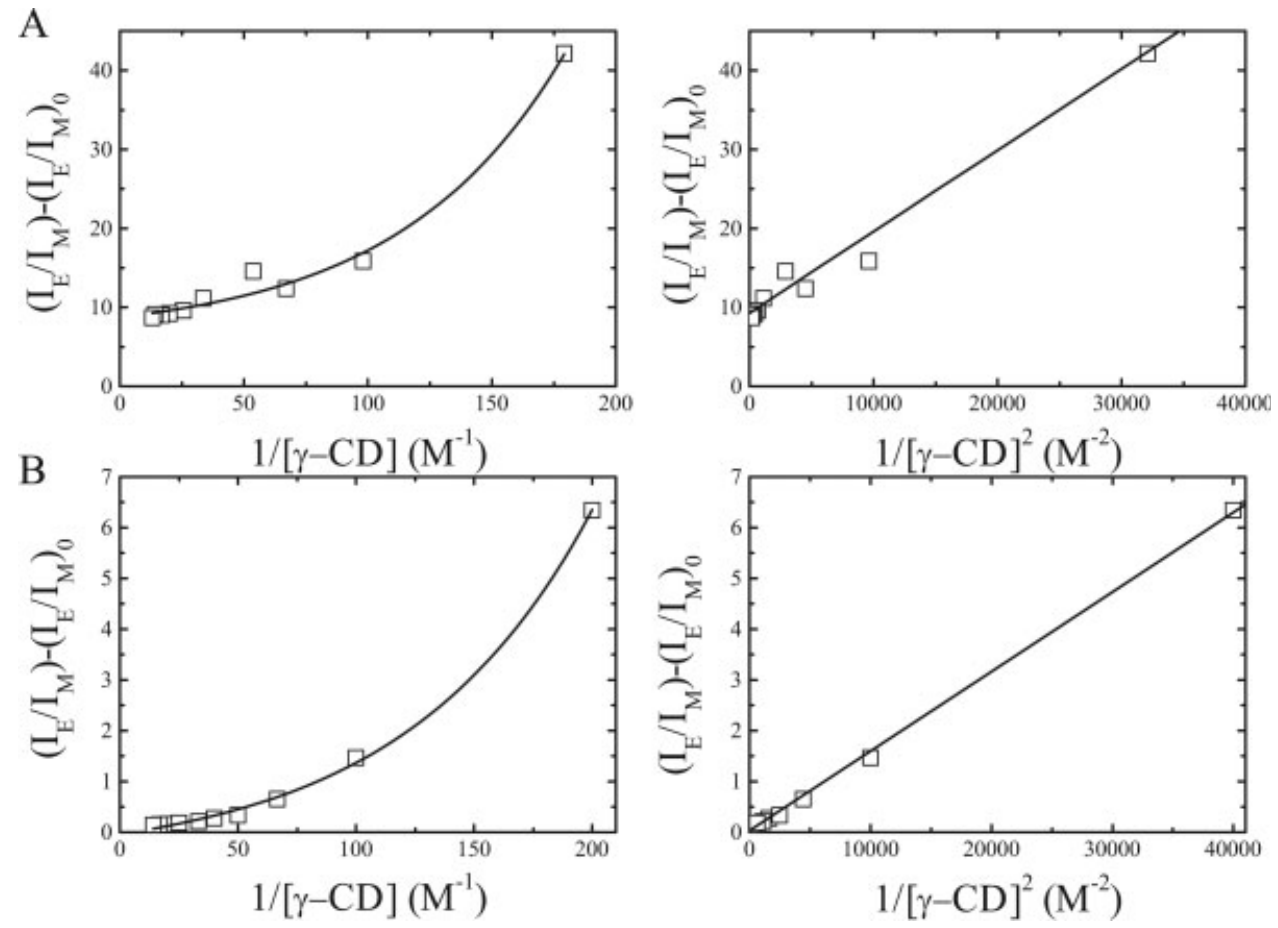

Figure 5. Benesi-Hildebrand plots for the (A) PAAMePy(2)77 and (B) PAAMePy(450)53 polymers as a function of the $1 /[\gamma-\mathrm{CD}]$ (right panels) and $1 /[\gamma-\mathrm{CD}]^{2}$ (left panels).

gressively decreases from 1.77 to 1.62 and from 1.75 to 1.58 for the low [PAAMePy(450)87] and high [PAAMePy(450)53] polymers, respectively. This shows that pyrene is sensing different polarity microenvironments [see Fig. 2(B) left panels]. In aqueous solutions the $\mathrm{PAAMePy}(450)$ polymers display $I_{1} / I_{3}$ ratio values at $\mathrm{pH}=3.5$ equal to $\approx 1.78$ [PAAMePy(450)87] and $\approx 1.75$ [PAAMePy(450)53]. ${ }^{42}$ These values are close to those obtained at low $\gamma$-CD concentrations showing that most of the Py groups are still in contact with water. At high $\gamma$-CD concentrations the $I_{1} / I_{3}$ ratio approaches values around 1.62 and 1.58 , for PAAMePy(450)87 and PAAMePy (450)53, respectively, indicating that pyrene is experiencing a less polar environment, since this last value is close to the $I_{1} / I_{3}$ value found for pyrene in glycerol $\left(I_{1} / I_{3}=1.60\right){ }^{6}$ These pronounced changes in the environment probed by the Py groups in PAAMePy(450) when compared with the $\mathrm{PAAMePy}(2)$ polymers reveal the different conformational nature adopted by the polymer chains resulting from interaction with $\gamma$-CD.

From the Benesi-Hildebrand equation, the $I_{1} /$ $I_{3}$ ratio has been used ${ }^{28,53,54}$ as a way to determine the stability constant ${ }^{53,54}$ of molecular complexes (involving $\mathrm{CDs}$ ) and of the involved stoichiometry. ${ }^{28,54}$ In this study the presence of excimer emission tail beneath the monomer band may have implications in the relative vibronic $I_{1} / I_{3}$ ratio. As a consequence, the Benesi-Hildebrand equations (eqs 1 and 2) have been used in terms of the $I_{\mathrm{E}} / I_{\mathrm{M}}$ ratio versus [CD]. For the $1: 1$ $\mathrm{Py}: \gamma-\mathrm{CD}$ complex, the equation is given by: ${ }^{28,54}$

$$
\frac{1}{R-R_{0}}=\frac{1}{K_{1}\left(R-R_{0}\right)[\mathrm{CD}]_{0}}+\frac{1}{R-R_{0}}
$$

where $R$ and $R_{0}$ are the $I_{\mathrm{E}} / I_{\mathrm{M}}$ ratio in aqueous solution in the presence of CD and $K_{1}$ is the equilibrium constant for the 1:1 complex. For the 2:1 Py: $\gamma$-CD complex, and assuming that $[1: 2]>[1: 1]$, the equation is now given by: ${ }^{28}$

$$
\frac{1}{R-R_{0}}=\frac{1}{K_{2}\left(R-R_{0}\right)[\mathrm{CD}]_{0}^{2}}+\frac{1}{R-R_{0}}
$$

where $K_{2}$ is the equilibrium constant for the 2:1 complex. The Benesi-Hildebrand plots for the 1:1 and 2:1 Py: $\gamma-C D$ complexes are presented in Figure 5 (left and right panels, respectively) for the PAAMePy(2)77 and PAAMePy(450)53 polymers. From Figure 5 it can be observed that, for the two polymers, no linear trend is observed from the $1 /\left(R-R_{0}\right)$ versus $1 /[\gamma-\mathrm{CD}]$ plot. However, when $1 /\left(R-R_{0}\right)^{2}$ versus $1 /[\gamma-\mathrm{CD}]^{2}$ is plot- 
ted a clear linear relationship is obtained, indicative of 2:1 Py: $\gamma$-CD complexes. Nevertheless, from time-resolved fluorescence data coexistence of $2: 1$ with $1: 1$ complexes is detected since an increase of the decay time value associated with the free monomers with the incremental addition of $\gamma$-CD is observed (see Fig. 6 and Time-Resolved Fluorescence Data-“Discussion" section).

As mentioned in the "Results" section, the addition of $\beta$-CD to the PAAMePy polymers induces minor changes in their photophysical properties. This behavior was previously observed in similar PAAMePy polymers with molecular weight of $150,000 \mathrm{~g} \mathrm{~mol}^{-1} \cdot{ }^{22}$ Different results were obtained by Haldar et al. ${ }^{27}$ where for a pyrene-end-capped poly(ethyleneoxide) polymer and by addition of $\beta$-CD a decrease of the $I_{\mathrm{E}} / I_{\mathrm{M}}$ ratio was found; a logical consequence of the encapsulation of a single pyrene with consequent decrease in excimer formation. The random nature of the pyrene labeled polymers investigated here is responsible for a more rich (complex) kinetics with a clear departure from the kinetic formalism involving two species. With the PAAMePy polymers, free and MAGRE monomers coexist with two conformationally different excimers, that is a 4 -species system. ${ }^{42}$ Indeed, it is reasonable to consider that $\beta$-CD preferentially forms 1:1 inclusion complexes with the free monomers; monomers which either in a globule or expanded conformation are more exposed and available to interact with the CD than the MAGRE monomers are, since these are found in a more hydrophobic environment and consequently less available to interact with the CDs. As a consequently and in view that the $\beta$ CD essentially encapsulates the free monomers, there are no significant changes in the observed photophysical parameters. In terms of the steady-state data, the formation of inclusion complexes with $\beta$-CD is confirmed by the slight decrease in the $I_{1} / I_{3}$ ratio; for the short chain polymers the $I_{1} / I_{3}$ ratio decreases from 1.83 (in water) to 1.78 (at high concentrations of $\mathrm{CD}$ ), whereas for the long chain polymers it varies between 1.78-1.67 and 1.75-1.70 (low and highlabeled polymers respectively). By comparing the variation of the $I_{1} / I_{3}$ ratio for the PAA$\mathrm{MePy}(2)$ polymers in the presence of $\beta$-CD and $\gamma-\mathrm{CD}$, an identical variation is observed, due to the fact that most of the labeled $\operatorname{PAAMePy}(2)$ polymers are single-labeled, ${ }^{42}$ i.e., form $1: 1$ Py:CD inclusion complexes. Application of eqs 1 and 2 to the PAAMePy polymers in the presence
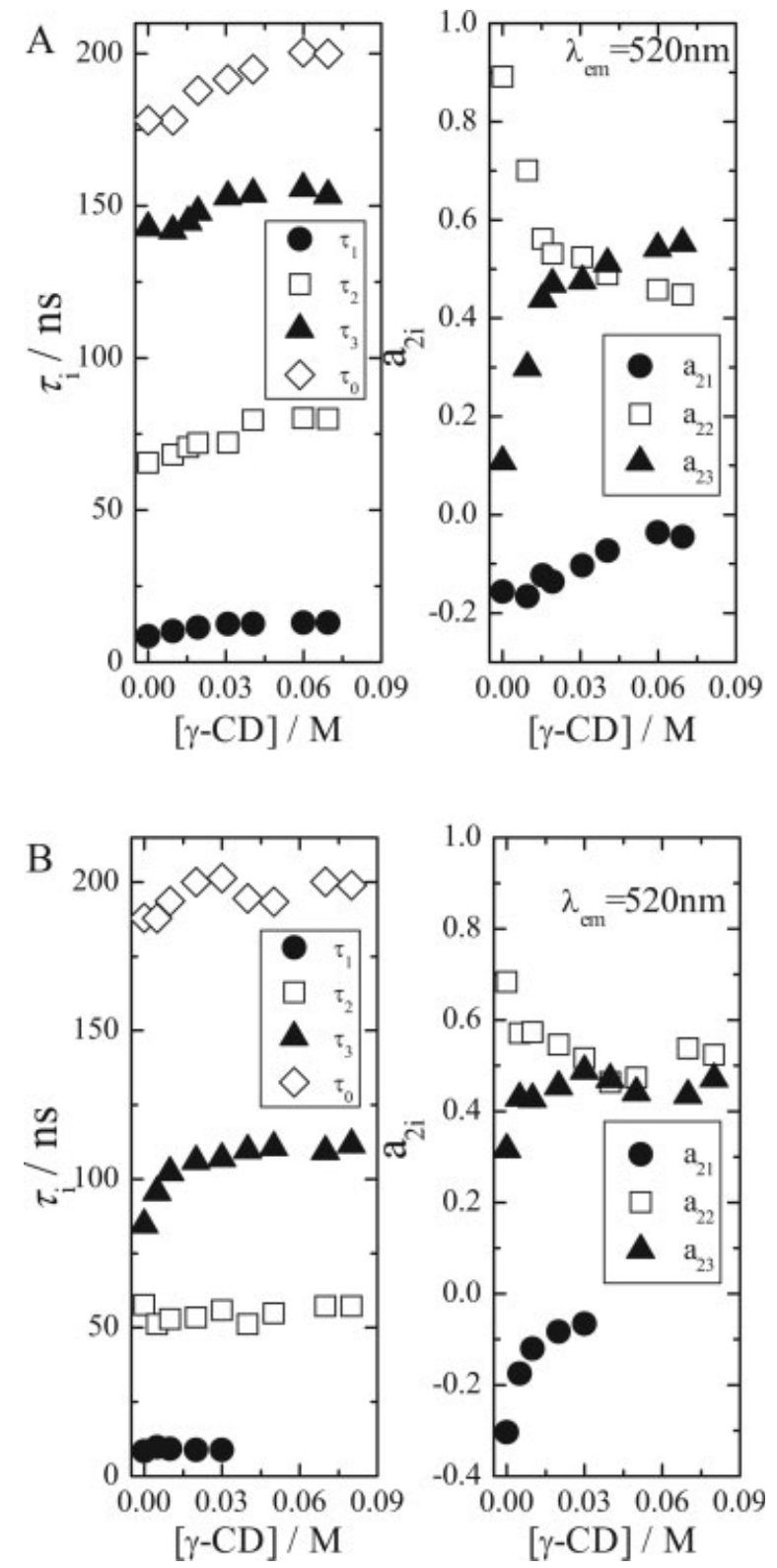

Figure 6. Fluorescence decay times $\left(\tau_{i}\right)$ and preexponential factors at $520 \mathrm{~nm}\left(a_{2 j}\right)$ as a function of $\gamma$-CD concentration for (A) PAAMePy(450)87 and (B) PAA$\mathrm{MePy}(2) 52$ polymers.

of $\beta$-CD revealed to be inconclusive, since in this case no significant changes in the photophysical properties of the polymers were observed.

\section{Time-Resolved Fluorescence Data}

Figure 6 shows the dependence of the decay times and pre-exponential factors with the $\gamma$-CD concentration for the $\mathrm{PAAMePy}(450) 87$ and PAAMePy(2)52 polymers. The increase in $\gamma$-CD 
concentration leads, for the two polymers, to an increase of the decay time values, a situation more evident for the longest decay time, $\tau_{0}$, associated with the isolated chromophores. The raise on the decay time values with $\gamma$-CD is related to the formation of $1: 1$ and $2: 1 \mathrm{Py}: \mathrm{CD}$ inclusion complexes. The gradual inclusion of $\mathrm{Py}$ groups into the CD cavity avoids the exposure to oxygen (an efficient fluorescence quencher), giving rise to higher fluorescence lifetime values. This is particularly perceptible for the decay times of the isolated chromophores $\left(\tau_{0}\right)$. Indeed, the presence of this decay time even at high concentrations of CD confirms the formation 1:1 Py:CD inclusion complexes.

The decay times $\tau_{2}$ and $\tau_{3}$ are associated to the existence of two conformational different excimers. The existence of two excimers in pyrene-based systems has been observed with oligomers $^{55-58}$ and polymers ${ }^{22,42}$ where the grafting of the pyrene units is made at the position 1 of the probe. Asymmetric and symmetric sandwich-like structure are associated, respectively, to the shorter $\left(\tau_{2}\right)$ and longer decay time $\left(\tau_{3}\right)$ excimers. ${ }^{42,57}$

It is also worth comment on the variation of the preexponential factors for the PAA$\mathrm{MePy}(450)$ polymers in Figure 6(A). The $a_{10}$ preexponential factor, associated with the fraction of isolated chromophores, ${ }^{17,42,43,47,48,59}$ decreases with the addition of $\gamma$-CD. The presence of $\gamma$-CD leads to an increase of the hydrophobic sites in solution (preferential location for the pyrene groups). Since the $\gamma$-CD cavity can accommodate two pyrene groups, the gradual encapsulation of these into the same $\gamma$-CD cavity leads to more formation of GSDs and less free monomers. It is once more worth noting that because of their location in a low-labeled region of the polymer chain, pyrene groups that are not able to form excimer-the free monomers-are still present, leading to the formation of 1:1 $\gamma$-CD:Py inclusion complexes. Moreover, with the addition of $\gamma$-CD, the preexponential factor $a_{21}$ becomes less negative and the sum of the preexponential factors at the excimer emission wavelength, $a_{2 j}$, gradually approaches 1 . However, even at high $\gamma$-CD concentration, a small negative preexponential value is still observed. With the previously investigated $\mathrm{PAAMePy}(150) 55$ polymer, ${ }^{22}$ with a PAA chain length three times smaller than PAA$\mathrm{MePy}(450) 53$ and identical degree of Py labeling, a negative pre-exponential was also observed. This suggests that this polymer behaves in many ways similarly to the long chain $\mathrm{PAAMePy}(450)$ polymers and that, in both cases, some pyrene groups are not involved in the inclusion complex formation and are still able to form excimer through a dynamic route. ${ }^{22}$ This behavior is opposite to that found with the short chain polymer (as will be discussed later) where no rise time was observed.

The addition of $\gamma$-CD leads to a decrease and to an increase of, respectively, the preexponential factors $a_{22}$ and $a_{23}$ (associated with the contributions of the excimers with asymmetric and symmetric sandwich-like geometry, respectively). This supports the preferential encapsulation of the symmetric sandwich-like pyrene excimer. By using induced circular dichroism (ICD) Kano et al. ${ }^{40,60}$ and Kobayashi et al. ${ }^{61}$ have studied the interaction of pyrene, and of 1,3di(2-pyrenyl)propane, with $\gamma$-CD. Based on the change of the sign in the ICD spectrum it was concluded that the dimer formed inside the $\gamma$ CD cavity had an asymmetric configuration, in apparent contrast with our results. However, the study with pyrene or pyrene-like (small) molecules clearly contrasts with pyrene-labeled polymers, which introduces an additional degree of complexity to the system.

With the PAAMePy(2) polymers, the decay times and preexponential factors change with $\gamma$ CD follow the same tendency as observed with the long chain PAAMePy(450) polymers (see Fig. 6 ). However, the most significant finding regarding the interaction between the $\operatorname{PAAMePy}(2)$ polymers and $\gamma-\mathrm{CD}$ is the fact that up to 0.01 and $0.03 \mathrm{M}$, the fluorescence decays become mono and biexponential at, respectively, the monomer and excimer emission wavelengths. At the monomer emission wavelength the decay time is associated to the emission of free monomers whereas at the excimer emission wavelength the two conformational different excimers are now the (only) emissive species. It is important to stress that the decay time associated with MAGRE monomers $\left(\tau_{1}\right)$ has now vanished and consequently the rise-time at the excimer emission is also absent at high $\gamma$-CD concentrations. This gives support to the fact that the two excimers are preformed in the ground-state. At low $\gamma$-CD concentrations, the presence of a negative preexponential at the excimer emission wavelength indicates that the pyrene groups are all not encapsulated by the $\gamma$-CD. With the gradual addition of $\gamma$-CD the $a_{21}$ preexponential factor becomes less negative (decrease of dynamic 
excimer contribution) and above 0.01 or $0.03 \mathrm{M}$ [PAAMePy(2)77 or $\mathrm{PAAMePy}(2) 52$, respectively] the sum of the preexponential factors at $520 \mathrm{~nm}$ becomes equal to 1 which eventually shows that all pyrene groups are now involved in the formation of inclusion complexes with the $\gamma$-CD.

\section{Energetics}

The dependence of the $I_{\mathrm{E}} / I_{\mathrm{M}}$ ratio with temperature can be presented by the so-called StevensBan plots, ${ }^{43,62}$ from which the values for the activation energy formation (slope of the low-temperature limit regime, LTL), $E_{\mathrm{a}}$, and the enthalpy (slope of the high-temperature limit regime HTL), $\Delta H$, of the excimer are obtained. ${ }^{43}$ However, as can be seen in Figure 7, the LTL is illdefined for $\mathrm{PAAMePy}(2) 52$, at $\mathrm{pH}=3.5$, since the transition temperature between the LTL and HTL regimes $\left(T^{*}\right)^{4,43}$ is found at $28-30{ }^{\circ} \mathrm{C}$. Consequently, what comes out from these plots is resumed to the enthalpy of excimer formation, with values of -23 and $-13.7 \mathrm{~kJ}$ mol in pure water and in the presence of $0.03 \mathrm{M} \gamma-\mathrm{CD}$, respectively. Although the interpretation of these plots is not as straightforward as it is in a Stevens-Ban plot associated with a generic Birks' kinetics, ${ }^{4}$ a significant decrease in the binding energies of the excimers is observed upon addition of $\gamma$-CD. In water, a predominance of the twisted-like con-

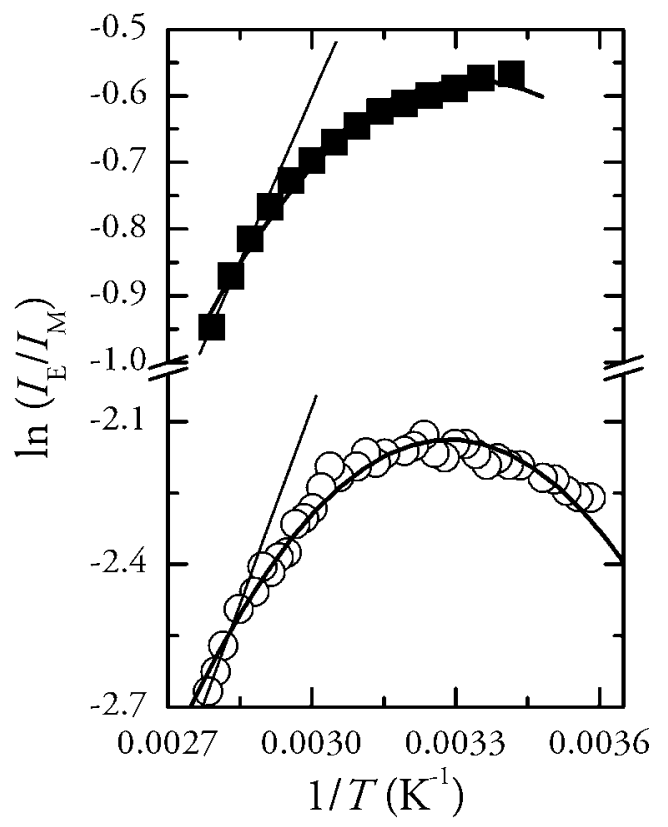

Figure 7. Plots of $\ln \left(I_{\mathrm{E}} / I_{\mathrm{M}}\right)$ versus $1 / T$ obtained for the PAAMePy(2)52 system with $0 \mathrm{M}(\mathbf{\square})$ and $0.03 \mathrm{M}$ (○) of $\gamma$-CD, at $\mathrm{pH}=3.5$.

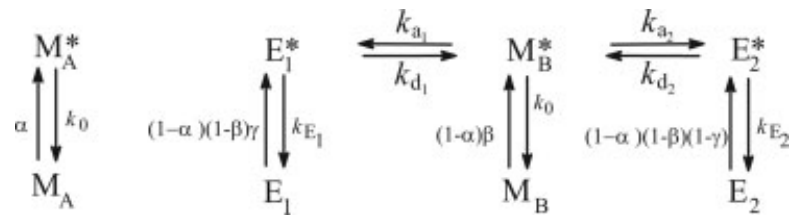

Scheme 2. Kinetic scheme for the PAAMePy polymers in water.

formation (more stable) over the parallel sandwich-like (less stable) conformation $\left(a_{22}>a_{23}\right)$ is observed..$^{42}$ For $[\gamma-\mathrm{CD}]=0.03 \mathrm{M}$ the $a_{22}$ and $a_{23}$ preexponential factors are equal, showing that the less stable excimer gains weight over the more stable excimer. This is most likely because of restrictions imposed by the polymer chain and by the presence of $\gamma$-CD. From the above, it can be concluded that the decrease in the absolute value of $\Delta H$ is related with the increase in the fraction of the less stable excimer.

\section{Kinetic Scheme in the Presence of $\gamma$-CD}

As mentioned, the kinetic scheme presented elsewhere ${ }^{22,42}$ and depicted in Scheme 2 is still valid in the presence $\gamma$-CD. This occurs with the PAAMePy(450) (over all range of $\gamma$-CD concentrations) and PAAMePy(2) polymers (at concentrations below 0.02 and $0.04 \mathrm{M}$ ). However, the data obtained at (only) two emission wavelengths is not sufficient to solve this kinetic scheme and to determine the association, dissociation, and decay rate constants $\left(k_{\mathrm{a} i}, k_{\mathrm{d} i}, k_{\mathrm{E} i}\right.$, respectively, where $i=1,2$ ) and the fractions of the ground-state species present in solution $(\alpha$, $\beta$, and $\gamma){ }^{42}$ This study is currently under progress using a procedure and methodology analogous to the one used in ref. 63 .

Nevertheless and for the short size chain polymers at $\gamma$-CD concentrations higher than 0.01 and $0.03 \mathrm{M}$-for the low- and high-labeled polymers, respectively- the kinetic behaviour is simplified and can be described by Scheme 3, where $\beta\left(=a_{10}\right), \alpha\left(=a_{22}\right)$, and $\gamma\left(=a_{23}\right)$ are the fractions of light that excite the free monomers $\left(\mathrm{M}_{\mathrm{A}}\right)$, and the excimers $\mathrm{E}_{1}$ and $\mathrm{E}_{2}$, respectively.

According to Scheme 3, the time-dependent profile at the monomer and excimer emission wavelengths can be described by eqs 3 and 4 , respectively.

$$
\begin{gathered}
I_{\mathrm{M}}(t)=I_{375 \mathrm{~nm}}(t)=a_{10} e^{-\lambda_{0} t} \\
I_{\mathrm{E}}(t)=I_{520 \mathrm{~nm}}(t)=a_{22} e^{-\lambda_{2} t}+a_{23} e^{-\lambda_{3} t}
\end{gathered}
$$

Journal of Polymer Science: Part A: Polymer Chemistry DOI 10.1002/pola 

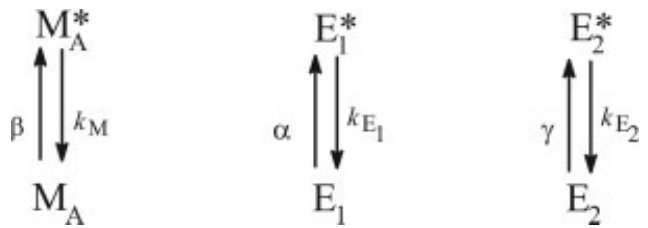

Scheme 3. Kinetic scheme in the presence of $\gamma-\mathrm{CD}$; see text for details.

where, $\lambda_{i}=\frac{1}{\tau_{i}}$.

Since in Scheme 3, the species are kinetically uncoupled the decay rate constants are given by:

$$
k_{i}=\frac{1}{\tau_{i}}
$$

The obtained rate constants are presented in Table 1. Up to $\gamma$-CD concentration of $0.01 \mathrm{M}$ [PAAMePy(2)77] or $0.03 \mathrm{M}$ [PAAMePy(2)52] the rate constants can be considered to be constant and independent of the $\gamma$-CD concentrations. The rate constant $\left(k_{0}\right)$ for the free monomers is found with values that can be found for pyrene substituted (in position 1) compounds. ${ }^{55,64,65}$ The rate constant of the more stable excimer $\left(k_{\mathrm{E} 1}\right)$ has a similar value to those reported for the PAAMePy(2) polymers in organic solvents (dioxane and methanol) $^{22}$ and also with other pyrene-labeled polymers. ${ }^{17,66,67}$ For the PAA$\mathrm{MePy}(2)$ polymers, the rate constants seem to be independent of the pyrene degree of labeling. This was also observed in organic solvents. ${ }^{42}$ It is also interesting to compare the values obtained for these two excimers in $\gamma$-CD cavities with analogous studies made with different hosting systems. In fact, a recent study on the incorporation of pyrene onto the cavities of different calix $[n]$ arene (where $n$ gives the diameter of the inner cavity) have showed that with $n=$
6 the dimer displays a lifetime of $65 \mathrm{~ns}$ and with $n=8$ the value is $130 \mathrm{~ns}^{68}$ This suggests that also in these types of cavities different type of dimers/excimers could be present and that the more stable excimer (twisted sandwich with a lifetime of ca. $60 \mathrm{~ns})^{42,57}$ is preferentially accommodated by the lower diameter calixarene whereas for the less stable excimer (parallel sandwich conformation with a longer lifetime $130-150 \mathrm{~ns}^{42,57}$ ) a calixarene with a higher cavity diameter is preferred. The analogy with the studied system seems evident, with the $\gamma$-CD cavity accommodating preferentially the less stable excimer.

\section{CONCLUSIONS}

The effect of the addition of $\gamma$-CD to poly(acrylic acid) polymers with long [PAAMePy(450)] and short [PAAMePy(2)] chain-size randomly labeled with pyrene, was investigated with fluorescence techniques. The addition of $\gamma$-CD showed to promote intermolecular interactions with the long chain polymers, while absence of interaction was observed with the short chain polymers. With the two polymers (low and high $M_{\mathrm{w}}$ ) the addition of CD leads to the formation of $1: 1$ and 1:2 $\gamma$-CD:Py inclusion complexes. The degree of dynamic versus static excimer formation also changes with the concentration of $\gamma-\mathrm{CD}$, with ground-state association gradually overcoming excimer formation from a dynamic mechanism. Nevertheless, with the long chain PAA$\mathrm{MePy}(450)$ polymers, dynamic excimer formation is still present, whereas with the short chain polymers it vanishes at high $\gamma$-CD concentrations. The existence of two excimers with dif-

Table 1. Rate Constants for Excimer Formation with Symmetric $\left(k_{\mathrm{E} 1}\right)$ and Asymmetric $\left(k_{\mathrm{E} 2}\right)$ Configurations and Free Monomers, $k_{0}$, for the PAAMePy(2)77 and PAAMePy(2)52 Polymers at Different $\gamma$-CD Concentrations, at $\mathrm{pH}=3.5$ and $\mathrm{T}=293 \mathrm{~K}$.

\begin{tabular}{cccccccc}
\hline Polymer & $\gamma-\mathrm{CD}(\mathrm{M})$ & $\tau_{0}(\mathrm{~ns})$ & $k_{0}\left(\mathrm{~ns}^{-1}\right)$ & $\tau_{\mathrm{E} 1}(\mathrm{~ns})$ & $k_{\mathrm{E} 1}\left(\mathrm{~ns}^{-1}\right)$ & $\tau_{\mathrm{E} 2}(\mathrm{~ns})$ & $k_{\mathrm{E} 2}\left(\mathrm{~ns}{ }^{-1}\right)$ \\
\hline PAAMePy(2)77 & 0.02 & 194 & 0.005 & 60 & 0.017 & 110 & 0.009 \\
& 0.03 & 198 & 0.005 & 60 & 0.017 & 115 & 0.009 \\
& 0.04 & 200 & 0.005 & 57 & 0.018 & 121 & 0.008 \\
PAAMePy(2)52 & 0.06 & 207 & 0.005 & 60 & 0.017 & 121 & 0.008 \\
& 0.04 & 195 & 0.005 & 51 & 0.020 & 110 & 0.009 \\
& 0.05 & 193 & 0.005 & 55 & 0.018 & 111 & 0.009 \\
& 0.07 & 200 & 0.005 & 57 & 0.018 & 109 & 0.009 \\
& 0.08 & 199 & 0.005 & 57 & 0.018 & 112 & 0.009 \\
\hline
\end{tabular}


ferent geometries was also observed from timeresolved fluorescence: twisted sandwich-like geometry (longer lived) and parallel sandwich-like geometry. The inclusion of two pyrene groups as a dimer into the CD cavity seems to favor the latter geometry.

The coexistence of the intra- with intermolecular polymeric interactions (induced by the presence of $\gamma$-CD) is found only with the high-molecular weight polymers, whereas the low-molecular weight polymers only intrapolymeric interactions are present.

Financial support from the Portuguese Science Foundation (FCT) through FEDER and POCI is acknowledged. T. Costa acknowledges FCT for a Ph. D. grant (SFRH/BD/17852/2004). The authors thank A. Francisco, Dr. S. Gago, and Prof. I. Gonçalves for their help in the synthesis of the labelled polymers.

\section{REFERENCES AND NOTES}

1. Jönsson, B.; Lindman, B.; Holmberg, K.; Kronberg, B. Surfactants and Polymers in Aqueous Solution; Wiley: Chichester, 1998.

2. Winnik, F. M. Chem Rev 1993, 93, 587-614.

3. Gilbert, A.; Baggott, J. Essentials of Molecular Photochemistry; Blackwell Scientific Publications: Oxford, 1991.

4. Birks, J. B. Photophysics of Aromatic Molecules; Wiley: London, 1970.

5. Karpovich, D. S.; Blanchard, G. J. J Phys Chem 1995, 99, 3951-3958.

6. Dong, D. C.; Winnik, M. A. Can J Chem Rev Can Chim 1984, 62, 2560-2565.

7. Miguel, M. D.; Burrows, H. D.; Formosinho, S. J.; Lindman, B. J Mol Struct 2001, 563, 89-98.

8. Winnik, F. M.; Winnik, M. A.; Ringsdorf, H.; Venzmer, J. J Phys Chem 1991, 95, 2583-2587.

9. Street, K. W.; Acree, W. E. Analyst 1986, 111, 1197-1201.

10. Castanheira, E. M. S.; Martinho, J. M. G.; Duracher, D.; Charreyre, M. T.; Elaissari, A.; Pichot, C. Langmuir 1999, 15, 6712-6717.

11. Valeur, B. In Molecular Luminescence Spectroscopy. Methods and Applications; Schulman, S. G., Ed.; Wiley-Interscience: New York, 1993; Part 3, Chapter 2, pp 25-84.

12. Kalyanasundaram, K.; Thomas, J. K. J Phys Chem 1977, 81, 2176-2180.

13. Kalyanasundaram, K.; Thomas, J. K. J Am Chem Soc 1977, 99, 2039-2044.

14. Turro, N. J.; Pierola, I. F. J Phys Chem 1983, 87, 2420-2423.

15. Turro, N. J.; Pierola, I. F. Macromolecules 1983, 16, 906-910.
16. Miguel, M. D. Adv Colloid Interface Sci 2001, 89, 1-23.

17. Seixas de Melo, J.; Costa, T.; Miguel, M. G.; Lindman, B.; Schillén, K. J Phys Chem B 2003, 107, 12605-12621.

18. Turro, N. J.; Arora, K. S. Polymer 1986, 27, 783796.

19. Arora, K. S.; Turro, N. J. J Polym Sci Part B: Polym Phys 1987, 25, 243-262.

20. Arora, K.; Turro, N. J. J Polym Sci Part A: Polym Chem 1987, 25, 259-269.

21. Anghel, D. F.; Alderson, V.; Winnik, F. M.; Mizusaki, M.; Morishima, Y. Polymer 1998, 39, 30353044 .

22. Seixas de Melo, J.; Costa, T.; Oliveira, N.; Schillén, K. Polym Int 2007, 56, 882-899.

23. Relogio, P.; Martinho, J. M. G.; Farinha, J. P. S. Macromolecules 2005, 38, 10799-10811.

24. Schillén, K.; Anghel, D. F.; Miguel, M. D.; Lindman, B. Langmuir 2000, 16, 10528-10539.

25. Anghel, D. F.; Toca-Herrera, J. L.; Winnik, F. M.; Rettig, W.; von Klitzing, R. Langmuir 2002, 18, 5600-5606.

26. Costa, T.; Schillén, K.; Miguel, M. D. G.; Lindman, B.; Seixas de Melo, J. In Coloides e Interfases; Salicio, M. M. V.; Moreno, M. D. M., Eds.; Ediciones Universidad Salamanca: Salamanca, 2005; pp 313-319.

27. Haldar, B.; Mallick, A.; Purkayastha, P.; Burrows, H. D.; Chattopadhyay, N. Indian J Chem Sect A: Inorg Bioinorg Phys Theor Anal Chem 2004, 43, 2265-2273.

28. Delapena, A. M.; Ndou, T.; Zung, J. B.; Warner, I. M. J Phys Chem 1991, 95, 3330-3334.

29. Xu, W. Y.; Demas, J. N.; Degraff, B. A.; Whaley, M. J Phys Chem 1993, 97, 6546-6554.

30. Dyck, A. S. M.; Kisiel, U.; Bohne, C. J Phys Chem B 2003, 107, 11652-11659.

31. Connors, K. A. Chem Rev 1997, 97, 1325-1357.

32. Szejtli, J. Chem Rev 1998, 98, 1743-1753.

33. Zung, J. B.; Delapena, A. M.; Ndou, T. T.; Warner, I. M. J Phys Chem 1991, 95, 6701-6706.

34. Liu, L.; Guo, Q. X. J Inclusion Phenom Macrocycl Chem 2002, 42, 1-14.

35. Yorozu, T.; Hoshino, M.; Imamura, M. J Phys Chem 1982, 86, 4426-4429.

36. Cox, G. S.; Turro, N. J.; Yang, N. C. C.; Chen, M. J. J Am Chem Soc 1984, 106, 422-424.

37. Park, J. W.; Song, H. J. J Phys Chem 1989, 93, 6454-6458.

38. Haldar, B.; Mallick, A.; Chattopadhyay, N. J Mol Liq 2004, 115, 113-120.

39. Duan, Q.; Miura, Y.; Narumi, A.; Shen, X.; Sato, S.; Satoh, T.; Kakuchi, T. J Polym Sci Part A: Polym Chem 2006, 44, 1117-1124.

40. Kano, K.; Matsumoto, H.; Yoshimura, Y.; Hashimoto, S. J Am Chem Soc 1988, 110, 204-209.

41. Werner, T. C.; Colwell, K.; Agbaria, R. A.; Warner, I. M. Appl Spectrosc 1996, 50, 511-516. 
42. Seixas de Melo, J.; Francisco, A.; Costa, T.; Maçanita, A.; Gago, S.; Gonçalves, I. S. Phys Chem Chem Phys 2007, 9, 1370-1385.

43. Costa, T.; Miguel, M. G.; Lindman, B.; Schillén, K.; Seixas de Melo, J. S. J Phys Chem B 2005, 109, 11478-11492.

44. Seixas de Melo, J.; Fernandes, P. F. J Mol Struct 2001, 565, 69-78.

45. Striker, G.; Subramaniam, V.; Seidel, C. A. M.; Volkmer, A. J Phys Chem B 1999, 103, 8612.

46. Chu, D. Y.; Thomas, J. K. J Am Chem Soc 1986, 108, 6270-6276.

47. Costa, T.; Miguel, M. G.; Lindman, B.; Schillén, K.; Lima, J. C.; Seixas de Melo, J. J Phys Chem B 2005, 109, 3243-3251.

48. Seixas de Melo, J.; Francisco, A.; Costa, T.; Gago, S.; Gonçalves, I. S. In Coloides e Interfases; Salicio, M. M. V.; Moreno, M. D. M., Eds.; Ediciones Universidad Salamanca: Salamanca, 2005; pp 291-298.

49. Buruiana, E. C.; Buruiana, T.; Strat, G.; Strat, M. J Polym Sci Part A: Polym Chem 2005, 43, 39453956.

50. Winnik, M. A.; Bystryak, S. M.; Liu, Z. Q.; Siddiqui, J. Macromolecules 1998, 31, 6855-6864.

51. Ezzell, S. A.; Hoyle, C. E.; Creed, D.; McCormick, C. L. Macromolecules 1992, 25, 1887-1895.

52. Nilsson, M.; Cabaleiro-Lago, C.; Valente, A. J. M.; Soderman, O. Langmuir 2006, 22, 86638669 .

53. Almgren, M.; Grieser, F.; Thomas, J. K. J Am Chem Soc 1979, 101, 279-291.

54. Indirapriyadharshini, V. K.; Karunanithi, P.; Ramamurthy, P. Langmuir 2001, 17, 4056-4060.
55. Zachariasse, K. A.; Kuhnle, W.; Leinhos, U.; Reynders, P.; Striker, G. J Phys Chem 1991, 95, 5476-5488.

56. Zachariasse, K. A.; Duveneck, G.; Busse, R. J Am Chem Soc 1984, 106, 1045-1051.

57. Zachariasse, K. A.; Duveneck, G.; Kuhnle, W. Chem Phys Lett 1985, 113, 337-343.

58. Zachariasse, K. A.; Duveneck, G.; Kuhnle, W.; Reynders, P.; Striker, G. Chem Phys Lett 1987, 133, 390-398.

59. Maçanita, A. L.; Horta, A.; Pierola, I. F. Macromolecules 1994, 27, 3797-3803.

60. Kano, K.; Matsumoto, H.; Hashimoto, S.; Sisido, M.; Imanishi, Y. J Am Chem Soc 1985, 107, 61176118.

61. Kobayashi, N.; Saito, R.; Hino, H.; Hino, Y.; Ueno, A.; Osa, T. J Chem Soc Perkin Trans 2 1983, 1031-1035.

62. Stevens, B.; Ban, M. I. Trans Faraday Soc 1964, 60, 1515-1523.

63. Seixas de Melo, J.; Maçanita, A. L. Chem Phys Lett 1993, 204, 556-562.

64. Duveneck, G. Georg-August-Universität, Göttingen: Göttingen, 1986.

65. Zachariasse, K. A.; Striker, G. Chem Phys Lett 1988, 145, 251-254.

66. Kanagalingam, S.; Ngan, C. F.; Duhamel, J. Macromolecules 2002, 35, 8560-8570.

67. Prazeres, T. J. V.; Beingessner, R.; Duhamel, J.; Olesen, K.; Shay, G.; Bassett, D. R. Macromolecules 2001, 34, 7876-7884.

68. Branco, T. J. F.; Ferreira, L. F. V.; do Rego, A. M. B.; Oliveira, A. S.; Da Silva, J. P. Photochem Photobiol Sci 2006, 5, 1068-1077. 